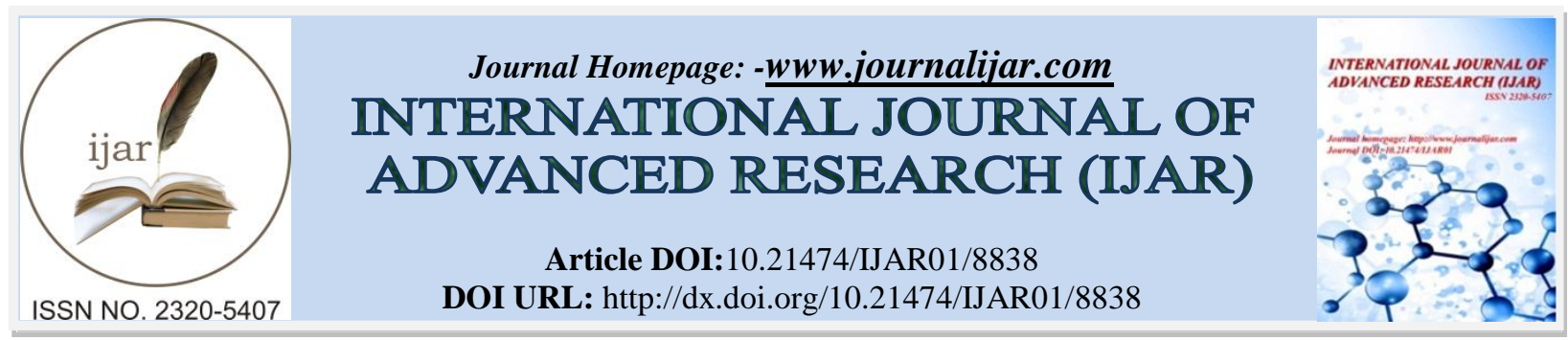

RESEARCH ARTICLE

\title{
COMPARATIVE EVALUATION OF ANTIMICROBIAL EFFICACY OF SODIUM HYPOCHLORITE, CHLORHEXIDINE, NEEM AND GREEN TEA AGAINST E. FAECALIS - AN IN VITRO STUDY.
}

Vrishali Shrigondekar, Jyoti Pawar, Meenal Gulve, Roshan Samuel, Swapnil Kolhe And Gayatri Aher.

\section{Manuscript Info}

\section{Manuscript History}

Received: 07 February 2019

Final Accepted: 09 March 2019

Published: April 2019

\section{Key words:-}

sodium hypochlorite, chlorhexidine, neem, green tea, E. faecalis.
Abstract

Aim and Objectives: To check the antimicrobial efficacy of sodium hypochlorite $(\mathrm{NaOCl})$, chlorhexidine $(\mathrm{CHX})$, neem and green tea against E. faecalis.

Materials and Methods: The irrigants were divided into four groups, Group I- NaOCl, Group II- CHX, Group III- Neem, Group IV- Green tea. Agar well diffusion test was used to study the antimicrobial efficacy against E. faecalis. The plate was incubated at $37^{\circ} \mathrm{C}$ for $24 \mathrm{hrs}$ in an incubator. The zone of inhibition was recorded, tabulated, and analyzed statistically using analysis of variance.

Results: All four irrigants showed well-defined and comparable zones of inhibition around their respective wells. There was significant difference between zone diameters of $\mathrm{CHX}$, neem, and $\mathrm{NaOCl}$ against E. faecalis $(\mathrm{p}<0.05)$.

Conclusion: From the present study, it can be concluded that neem leaf extract shows comparable zones of inhibition with that of chlorhexidine and sodium hypochlorite.

Copy Right, IJAR, 2019,. All rights reserved.

\section{Introduction:-}

Microorganisms are the major causative factors associated with endodontic treatment failures. ${ }^{1}$ Adequate cleaning and shaping in conjunction with effective irrigation protocol is an absolute necessity in eliminating microorganisms from the complex root canal system. ${ }^{2}$ Although bio-mechanical preparation of root canal reduces the number of bacteria, irrigants and intracanal medicament with antibacterial action are necessary for the disinfection of root canal system. $^{3}$ The gold standard among those are sodium hypochlorite $(\mathrm{NaOCl}), 2 \%$ solution of chlorhexidine and calcium hydroxide, which vary in their antibacterial activity. ${ }^{4}$

Sodium hypochlorite is the most commonly used irrigating solution since its introduction in 1936 by Walker. Its superior properties of tissue dissolution and antibacterial efficacy make it the irrigating solution of choice. However, it has a few shortcomings which are high toxicity, reduction in elastic modulus as well as flexural strength of dentin, corrosive to instruments, unpleasant taste and inability to remove smear layer. ${ }^{5,6}$

Chlorhexidine is another one of the most widely used root canal irrigant and is a bactericidal agent. Its interaction and uptake by bacteria were studied initially by Hugo and Longworth, who found that uptake of CHX by Escherichiacoliand Staphylococcus aureuswas very rapid and dependent on CHX concentration and $\mathrm{pH}^{7}{ }^{7}$ Its property of substantivity enables it to prevent bacterial colonization within the root canal system and hence is used as an intracanal irrigant. ${ }^{8}$ 
There is a constant increase in antibiotic resistant strains and the side effects caused by synthetic irrigants, these factors have led to the search for herbal alternatives.

An herbal medicine is defined as a plant-derived substance which contains raw ingredients from one or multiple plants with therapeutic uses (WHO). ${ }^{9}$

The advantageous reasons of using herbal irrigants are low toxicity and lack of microbial resistance and easy availability. ${ }^{10}$

Neem or Azadirachtaindica has shown to be effective against various microorganisms found in the oral microflora such as E.faecalis and Candida albicans. Its excellent antibacterial properties make it a material of choice for root canal irrigation and also an alternative to harmful chemical irrigants such as $\mathrm{NaOCl} .{ }^{11,12}$

Green tea polyphenols are the traditional and most widely consumed beverage obtained from Camellia sinensis. Cathechins and flavins are present in green tea, and these are considered as microbiologically active ingredients. ${ }^{13,14}$ Enterococcus faecalisis part of the human normal flora and an important pathogen in opportunistic infections in the root canal system. Eradication of E. faecalisfrom the root canal remains a challenge, since it is resistant to a variety of antimicrobial agents. Studies have also shown that E. faecalismay be one of the reasons of failure of endodontic treatments. ${ }^{15}$

Thus, the aim of the study was to assess the antimicrobial efficacy of conventional irrigants that is, $\mathrm{NaOCl}$ and $\mathrm{CHX}$ and alternative herbal irrigantsneem and green tea against E. faecalis in an in-vitro condition.

\section{Materials and Methodology:}

Preparation of Herbal Extracts:

$120 \mathrm{gm}$ of pure neem powder (Himalaya, India) was mixed with $2 \mathrm{ml}$ of $10 \%$ dimethyl sulfoxide solution (DMSO) (MERCK, Specialty Pvt. Ltd.,) liquid. This was stirred for $2 \mathrm{~min}$ and then passed through fast filter paper. The strained liquid was collected and used as sample.

$20 \mathrm{gm}$ of green tea powder (Organic India) was boiled for $5 \mathrm{~min}$ in $100 \mathrm{ml}$ of distilled water and filtered. This filtered solution was kept overnight and then mixed with $2 \mathrm{ml}$ of $10 \%$ DMSO solution and used as sample.

The irriganting solutions were divided into four groups:

Group I: $3 \% \mathrm{NaOCl}$

Group II: $2 \%$ CHX

Group III: Neem

Group IV: Green tea

\section{Agar Diffusion Test:}

Agar plates were prepared. Wells of $6 \mathrm{~mm}$ diameter were punch cut on the agar surfaces. Depending upon the groups, irrigants were pipetted into the agar well using sterile micropipette, and the plates were incubated at $37^{\circ} \mathrm{C}$ for $24 \mathrm{hrs}$ in an incubator. After incubation, plates were assessed for zones of inhibition. The diameter of the zone of inhibition was recorded in millimeters, using an inhibition zone measuring scale (Fig. 1). 


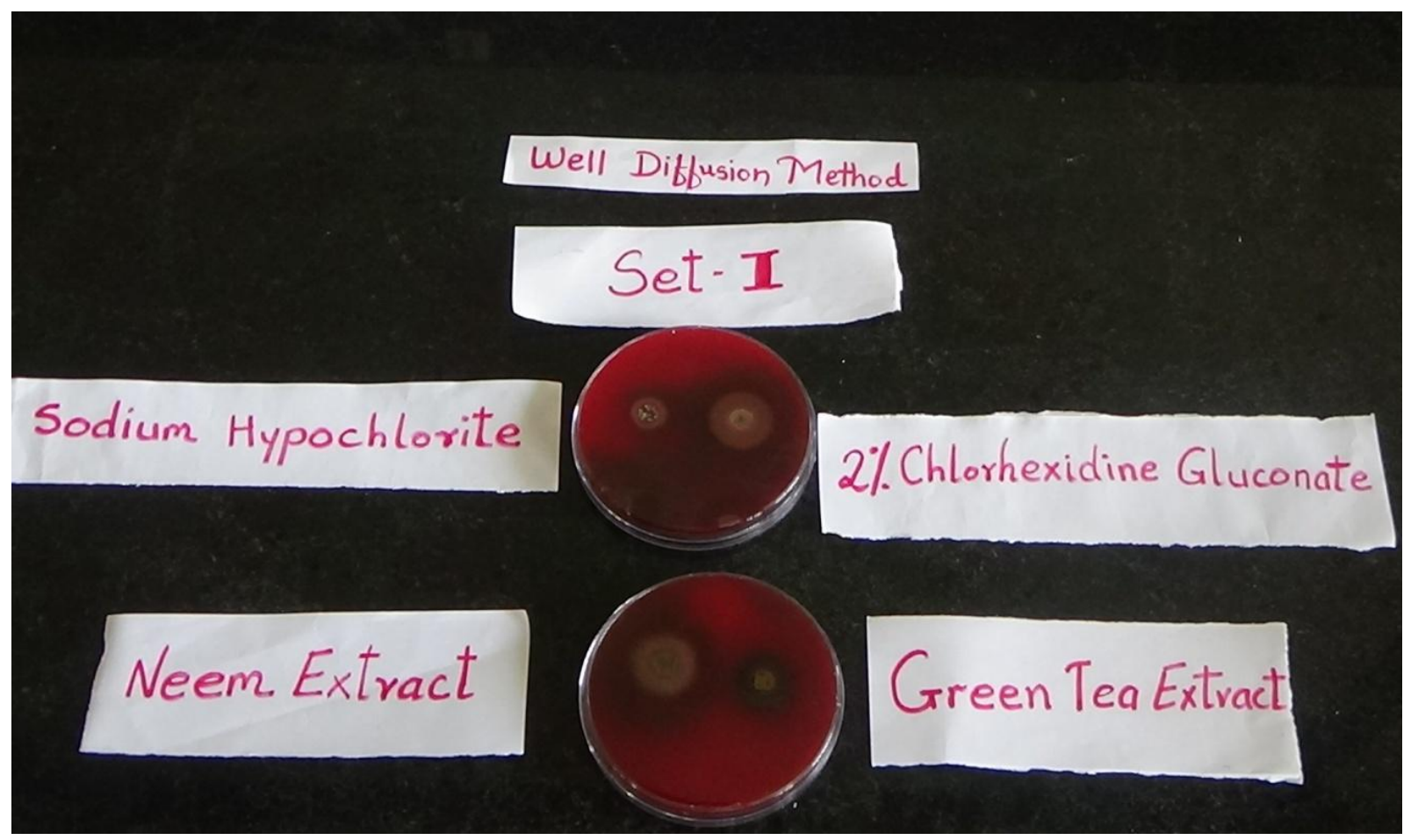

Results: (Table 1)
\begin{tabular}{|l|l|l|}
\hline SR. NO & IRRIGANTS & $\begin{array}{l}\text { ZONE OF INHIBITION } \\
\text { (DIAMETER IN MM) }\end{array}$ \\
\hline 1. & Sodium hypochlorite & $15.75 \mathrm{~mm}$ \\
\hline 2. & Chlorhexidine & $24.5 \mathrm{~mm}$ \\
\hline 3. & Neem & $20.5 \mathrm{~mm}$ \\
\hline 4. & Green tea & $6 \mathrm{~mm}$ \\
\hline
\end{tabular}

The antimicrobial activity of chlorhexidine was more than other agents. The antimicrobial activity of neem was comparable with that of $\mathrm{CHX}$ and there was no significant difference between the two. Green tea showed the least antimicrobial activity of all.

\section{Statistical Analysis:}

The results were tabulated and statistically analyzed using analysis of variance.

\section{Discussion:-}

Enterococcus faecalis is a saprophytic component of enteric flora and is the most common bacterium isolated from endodontic re-treatment of apical periodontitis, either as a single organism or as a major component of the flora. Studies have shown that E. faecalis can colonize medicated root canals with biofilm formation. ${ }^{16} \mathrm{E}$. faecalis has been shown to be associated with failed endodontic cases and has the ability to invade whole length of dentinal tubules to $1100 \mu \mathrm{m}$ or close to the cementum. It is also important to validate the bactericidal action of different disinfection methods using a resistant microorganism such as E. faecalis. ${ }^{17}$ Hence, E. feacalis is used in studies regarding the efficacy of endodontic irrigation solutions in cleaning the root canal systems.

This study employed agar diffusion method to evaluate the antimicrobial activity as several studies previously have used this technique. Although it is a reliable method formation of zones of inhibition may be altered due to variation in agar medium, bacterial strains, cellular density, and diffusion capacity of the agent. ${ }^{18}$

Sodium hypochlorite, the most commonly used root canal irrigant has broad spectrum of antimicrobial activity and excellent pulpal tissue dissolving potential. But its cytotoxicity due to its $\mathrm{pH}$ of 11-12 causes oxidation of proteins resulting in heamolysis and necrosis. Several hypochlorite accidents such as damage to patient's clothing, patient's 
or operator's eye, air emphysema when injected in root canals and allergic reaction to the irrigant. ${ }^{19}$ These disadvantages led to the need to identify a biocompatible and effective root canal irrigant.

The antimicrobial property of $2 \%$ chlorhexidinedigluconate could be because, CHX a positively charged hydrophobic and lipophilic molecule interacts with the negatively charged phospholipids and lipopolysaccarides on the cell membrane of bacteria, thereby altering the cell osmotic equilibrium. 2\% CHX is bactericidal as prercipitation of the cytoplasmic contents occurs, which results in cell death. Though CHX is being considered as one of the ideal intracanalirrigants available today, it has shown drawbacks like tissue irritaion and reactive oxygen species formation. ${ }^{20}$

The use of neem as an endodontic irrigant may be advantageous because neem is an excellent antioxidant with a very high biocompatibility, and thus there is no risk of tissue toxicity with its use. Biocompatibility of neem to the human periodontal ligament fibroblasts has already been proved, and this is an important factor favoring its clinical application in endodontics. However, the limitation of using this wonder drug is its characteristic bitter taste, which is because of the nimbidin present in neem. This drawback can be overcome by incorporating sweeteners into the neem extract. Present study showed that the antimicrobial efficacy of neem comparable with CHX and it was more than that of sodium hypochlorite and green tea.

Present study is in accordance with the study conducted by Hegde et al. in 2013 who compared the antibacterial efficacy of $2 \%$ sodium hypochlorite, propolis, neem leaf extract, turmeric and liquorice against E. faecalis and C. albicans, using the agar diffusion method. They concluded in their study that the neem leaf extract showed the highest zone of inhibition against E. faecalis and C. albicans. ${ }^{21}$

Green tea extracts (GTEs) contain catechin, which is one of the polyphenols from green tea. It has been reported that GTEs have remarkable anti-inflammatory, antioxidant and anti-cariogenic effects in a number of animal tumors, cell culture system, and epidemiological studies. ${ }^{22}$

\section{Conclusion:-}

Within the limitations of the study, antimicrobial activity of neem was comparable with that of CHX. Green tea also showed some antimicrobial activity. Thus it can be concluded that herbal products used for root canal irrigation will prove to be preferable considering the various disadvantages of $\mathrm{NaOCl}$ and $\mathrm{CHX}$. Further research is required to recommend the use of herbal alternatives as a root canal irrigant.

\section{References:-}

1. Narayanan LL, Vaishnavi C. Endodontic microbiology. J Conserv Dent2010;13(4):233-9.

2. Byström A, Sundqvist G. Bacteriologic evaluation of the efficacy of mechanical root canal instrumentation in endodontic therapy. Scand J Dent Res 1981;89:321-8.

3. Gomes BP, Souza SF, Ferraz CC, Teixeira FB, Zaia AA, Valdrighi L, et al. Effectiveness of $2 \%$ chlorhexidine gel and calcium hydroxide against Enterococcus faecalisin bovine root dentine in vitro. IntEndod $\mathrm{J}$ 2003;36:267-75.

4. Silva FB, Almeida JM, Sousa SM. Natural medicaments in endodontics - A comparative study of the anti-inflammatory action. Braz Oral Res 2004;18:174-9.

5. McComb D, Smith DC. A preliminary scanning electron microscopic study of root canals after endodontic procedures. J Endod 1975;1:238-42.

6. Oncag O, Cogulu D, Uzel A, Sorkun K. Efficacy of propolis as an intracanal medicament against Enterococcus faecalis. Gen Dent 2006;54:319-22.

7. Hugo WB, Longworth AR. Some aspects of the mode of action of chlorhexidine. J Pharm Pharmacol 1964;16:655-62.

8. Love RM. Enterococcus faecalis: A mechanism for its role in endodontic failure. IntEndod J 2001;34:399-405.

9. Parle M, Bansal N. Herbal medicines: Are they safe? Nat Prod Radiance 2006;5:6-14.

10. Prabhakar J, Senthilkumar M, Priya MS, Mahalakshmi K, Sehgal PK, Sukumaran VG. Evaluation of antimicrobial efficacy of herbal alternatives (Triphala and green tea polyphenols), MTAD, and 5\% sodium hypochlorite against Enterococcus faecalisbiofilm formed on tooth substrate: An in vitro study. J Endod 2010;36:83-6. 
11. Karimi K. The impact of current alternative herbal remedies on dental patient management. Gen Dent 1999;47:264-6.

12. Bohora A, Hegde V, Kokate S. Comparison of antibacterial efficacy of neem leaf extract and $2 \%$ sodium hypochlorite against E. faecalis, C. albicansand mixed culture - An in vitro study. Endodontology 2010;22:8-12.

13. Hamilton-Miller JM. Anti-cariogenic properties of tea (Camellia sinensis). J Med Microbiol 2001;50:299-302.

14. Smullen J, Koutsou GA, Foster HA, Zumbé A, Storey DM. The antibacterial activity of plant extracts containing polyphenols against Streptococcus mutans. Caries Res 2007;41:342-9.

15. Castilho AL, Saraceni CH, Díaz IE, Paciencia ML, Suffredini IB. New trends in dentistry: plant extracts against Enterococcus faecalis. The efficacy compared to chlorhexidine. Braz Oral Res 2013;27(2):109-115.

16. Distel JW, Hatton JF, Gillespie MJ. Biofilm formation in medicated root canals. J Endod 2002;28:689-93.

17. Vatkar NA, Hegde V, Sathe S. Vitality of Enterococcus faecalis inside dentinal tubules after five root canal disinfection methods. J Conserv Dent 2016,19:445-9.

18. Gupta N, Singh N, Thaper B. Effect of addtion of $2 \%$ chlorhexhidinegluconate, clcium hydroxide, and tetracyclin powder on antimicrobial activity of mineral trioxide aggregate. Endodontology 2016;28:23-6.

19. Sundaram, D., Retna, K.N. and Kannan, V. A comparative evaluation on antimicrobial effect of honey, neem leaf extract and sodium hypochlorite as intracanalirrigant: an ex-vivo study. J ClinDiagn Res 2016:10.

20. Martina L, Ebenezar A, Ghani M. An in vitro comparative antibacterial study of different concentrations of green tea extracts and 2\% chlorhexidine on Enterococcus faecalis. SEJ 2013;3: 120-123.

21. Singh H, Kaur M, Dhillon JS, Batra M, Khurana J. Neem: a magical herb in endodontics. Stomatological Dis Sci 2017;1:50-4.

22. Bhargava K, Kumar T, Aggarwal S, Zinzarde S, Sanap A, Patil P. Comparative evaluation of the antimicrobial efficacy of neem, green tea, triphala and sodium hypochlorite: An in vitro study. J Dent Res Rev 2015;2:13-6. 